\title{
Idiopathic Gingival Fibromatosis: Review of Literature and A Case Report
}

\author{
Singhal $\mathbf{R}^{1}$, Rozra S ${ }^{2}$, Bhagol $\mathbf{A}^{3}$
}

\section{Abstract}

Idiopathic Gingival Fibromatosis (IGF) is a rare condition of gingival enlargement that is characterized by gingival enlargement of normal colour and firm consistency that is non-haemorrhagic and asymptomatic. The purpose of this article is to report a case of 6-year old male child and review the literature related to IGF.

Keywords: Idiopathic gingival fibromatosis, Gingival enlargement, Hereditary gingival fibromatosis, Gingivomatosis, familial elephantiasis

\section{${ }^{1} \mathrm{MDS}$}

Demonstrator

Department of Pedodontics \& Preventive Dentistry Postgraduate Institute of Dental Sciences,

Rohtak, Haryana, INDIA

\section{${ }^{2} \mathrm{MDS}$}

Dental Surgeon

Rohtak, Haryana, INDIA

${ }^{3} \mathrm{MDS}$

Assistant Professor

Department of Oral and Maxillofacial Surgery

Postgraduate Institute of Dental Sciences,

Rohtak, Haryana, INDIA

\section{Contact Author}

Dr Ruchi Singhal singhal84.ruchi@gmail.com

J Oral Health Comm Dent 2013;7(3)174-177

\section{INTRODUCTION}

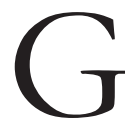
ingival enlargement is the - overgrowth of the gingiva char acterized by an expansion and accumulation of the connective tissue with occasional presence of increased number of cells (1). The most common forms of gingival enlargement are induced by several factors such as inflammation, leukaemia, drugs and inheritance (2). Idiopathic Gingival Fibromatosis (IGF) is a rare condition of gingival enlargement that is characterized by gingival enlargement of normal colour and firm consistency that is nonhaemorrhagic and asymptomatic $(3,4)$.

The aim of this article is to highlight the diagnosis, clinical features and management of a rare case of idiopathic gingival fibromatosis in a 6 year old boy.

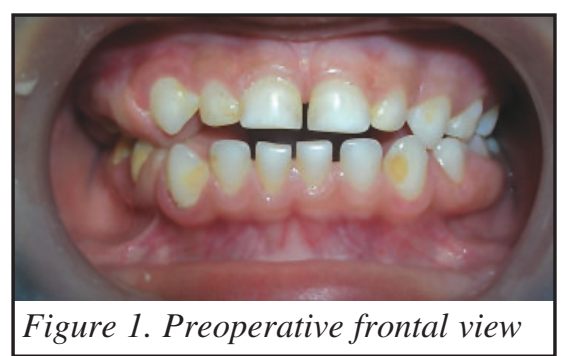

\section{CASE REPORT}

A six year old male child reported with the chief complaint of slow growing, non-tender gingival enlargement since birth. According to his parents the enlargement became more pronounced at the time of eruption of deciduous teeth. The major concern of the patient and family was esthetic and functional problems including mastication, speech, and oral hygiene. There was no history of epilepsy or long term medication for any other disease. Family and the prenatal-natal history was non contributory. Skeletal growth of the child was normal.

The patient had convex facial profile with incompetent lips and the nasal bridge was flat. Intraoral examination revealed pale-

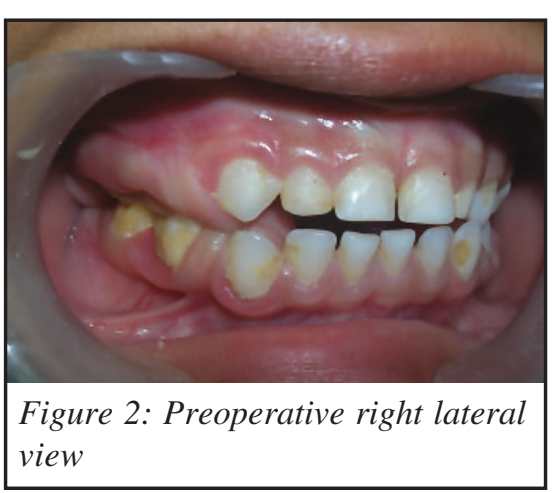




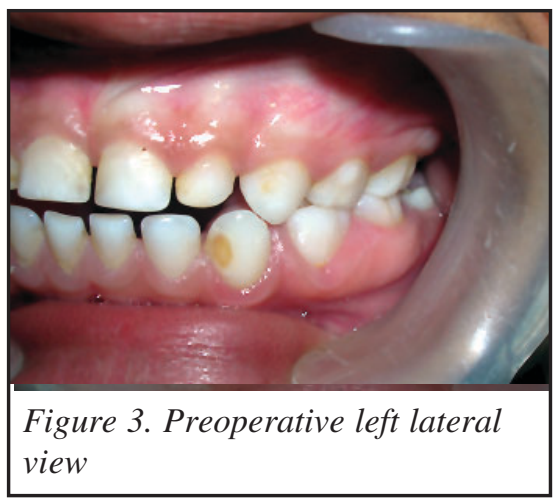

pink, firm generalized gingival swelling covering almost all deciduous posterior teeth with minimal involvement on upper left side (Figure 1-5). Gingival enlargement enclosed the major surface of the teeth present except the incisal/occlusal surfaces.Because of the enlarged gingival tissue, the patient was not able to occlude properly on the right posterior region (Figure 1,2).

After investigations like orthopantomogram and routine blood

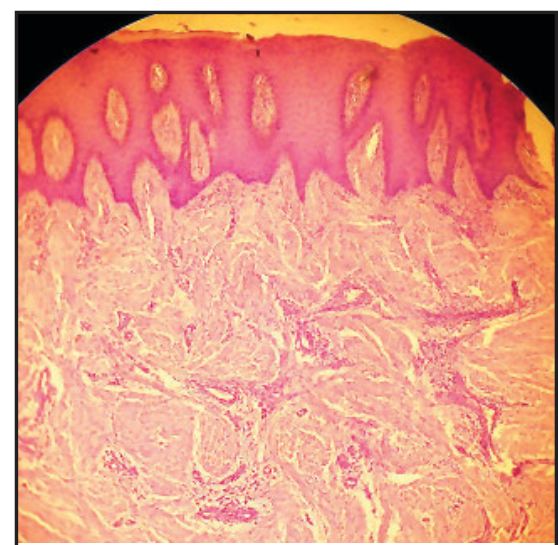

Figure 7. Histopathological view showing thick fibrous connective tissue with dense collagen fibre bundles

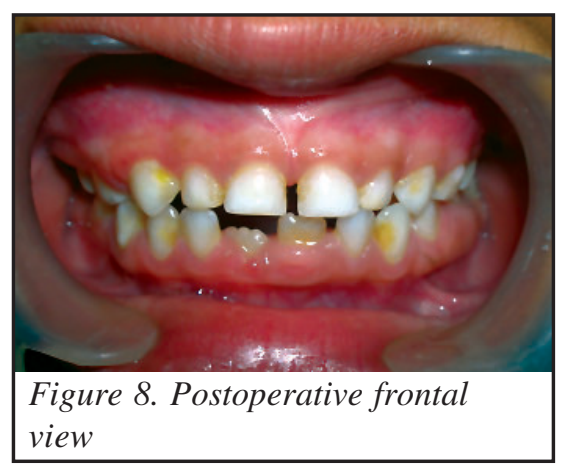

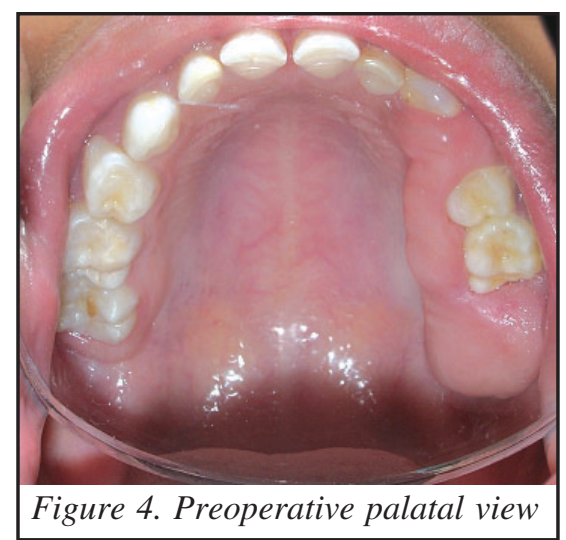

investigations including blood sugar level study-casts were prepared. Orthopantomogram were taken to rule out bony changes, displacement and resorption of the teeth. The results of the hematological investigations showed no abnormality. As the medical, family, prenatal and drug histories were non-contributory, other reasons of gingival hyperplasia were excluded and the case was diagnosed as idiopathic gingival fibromatosis.

The case was planned for segmental gingivectomy of the hyperplastic tissue. After initial diagnosis and treatment planning, routine oral hygiene instructions were given and oral prophylaxis was completed. Considering the size and extent of gingival enlargement, a quadrant-wise gingivectomy was performed under local anaesthesia (Figure 6). An external bevel gingivectomy was done in three quadrants excluding upper left side with an interval of about one month in between each surgery.

Surgeries were followed by histopathological examination of the excised tissue and postoperative care with regular follow up. Final postoperative result was acceptable

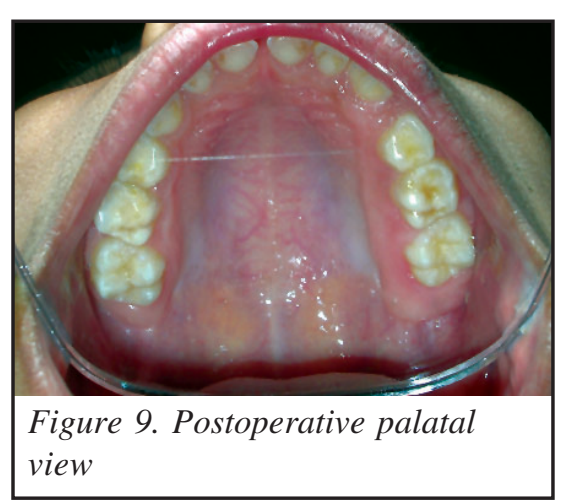

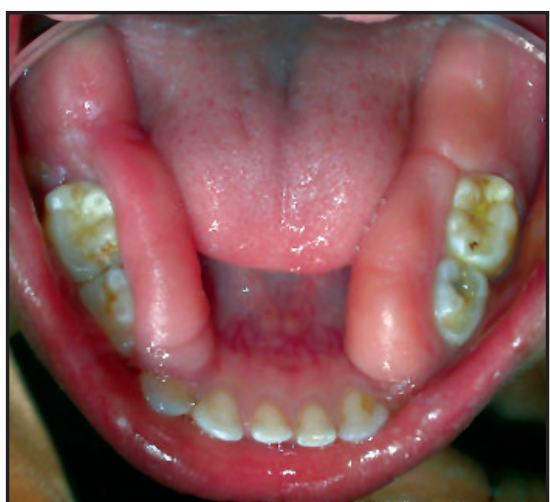

Figure 5. Preoperative lingual view

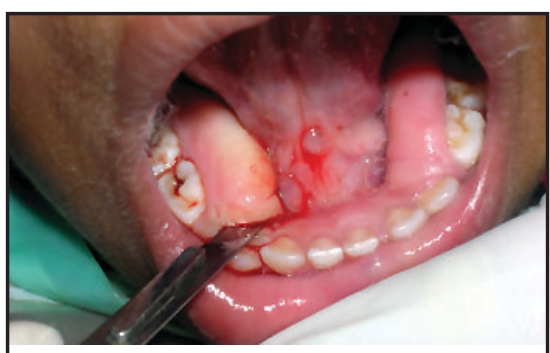

Figure 6. Segmental gingivectomy performed on lower right side.

gingival contour and patient was able to maintain oral hygiene and was well satisfied with results (Figure 7-10). Histopathological examination showed hyperparakeratinized hyperplastic stratified squamous epithelium and thick fibrous connective tissue with dense collagen fibre bundles (Figure 7).

\section{REVIEW OF LITERATURE}

Gingival fibromatosis (GF) is a heterogeneous group of disorders characterized by progressive enlargement of the gingiva caused by an increase in submucosal connective tissue elements (5).

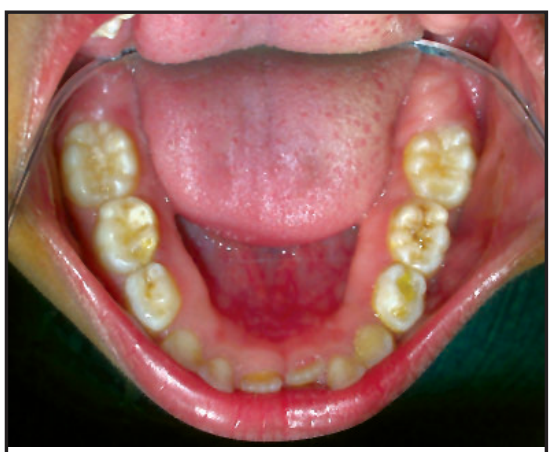

Figure 10. Postoperative lingual view 


\section{SYNONYMS}

Synonyms of GF include gingivomatosis, diffuse fibroma, hereditary gingival fibromatosis, familial elephantiasis, Idiopathic fibromatosis, elephantiasis gingivae, congenital hypertrophy of the gingiva, fibromatosis gingivae, gigantism of the gingiva, symmetric fibroma of the palate, congenital macrogingivae, hereditary gingival hyperplasia, and hypertrophic gingival $(2,6-8)$.

\section{CLINICAL FEATURES}

Idiopathic gingival fibromatosis is a slowly progressive benign enlargement that affects the marginal gingiva, attached gingiva and interdental papilla (9). It varies from minimal involvement of only the tuberosity area and the buccal gingiva around the lower molars to generalized enlargement inhibiting eruption of teeth $(3,8,10,11)$. The hyperplastic gingiva is pale-pink, firm, leathery in consistency that is nonhemorrhagic and asymptomatic. Males and females are equally affected at a phenotype frequency of 1:175,000 $(6,11)$.

Although gingival tissue may appear nor$\mathrm{mal}$ at birth, hyperplastic gingival fibromatosis may become evident with the eruption of primary or permanent dentition, suggesting a trauma -induced tissue reaction during the eruption (4,6,7,12-14). Furthermore, the presence of teeth seems to be necessary for HGF to occur because the condition disappears or recedes with the loss of the teeth $(6,15)$.

\section{COMPLICATIONS}

The gingival enlargement results in both esthetic and functional problems for affected individuals. The most common effects are diastemas, malpositioning of teeth, prolonged retention of primary dentition, delayed eruption, cross and open bites, prominent lips and open lip posture (3,4,11-14,16-21). Although the gingival enlargement does not directly affect the alveolar bone, the gingival swelling may increase the bacterial plaque accumulation, inducing periodontitis, bone resorption and halitosis (2). In extreme cases of massive gingival enlargement, an affected child usually develops abnormal swallowing pattern and experiences difficulty in speech and mastication (7).

\section{ETIOLOGY}

Idiopathic gingival fibromatosis is a rare hereditary condition that has no definite cause. The condition may manifest as an autosomal-dominant or, less commonly, an autosomal-recessive mode of inheritance, either as an isolated disorder or as part of a syndrome $(3,6)$. Syndromic gingival fibromatosis has been associated with ancillary features such as hypertrichosis, mental retardation, epilepsy, progressive sensorineural hearing loss and abnormalities of the extremities, particularly of the fingers and toes $(11,21,22)$. Autosomaldominant forms of gingival fibromatosis, which are usually nonsyndromic, have been genetically linked to the chromosome 2p21-p222 and 5q13-q22 (23). Recently, a mutation in the son of sevenless-1 (SOS1) gene has been suggested as a possible cause of isolated (nonsyndromic) gingival fibromatosis, but no definite linkage has been established (24). Although over the past few years increasing efforts have been made to understand the genetic, molecular and cellular basis of gingival enlargement of IGF patients, it has been impaired by the intense clinical, genetic and biologic heterogeneity of the disease.

There are many syndromes associated with IGF like Zimmermann- Laband syndrome, Rutherfurd syndrome, MurrayPuretic-Drescher syndrome, Cross syndrome, Prune belly syndrome, Ramon syndrome, Juvenile-hyaline syndrome and Jones syndrome $(2,5,7,23,25)$.

\section{INCIDENCE}

The number of patients with this oral lesion has greatly increased in the last three decades. Hereditary GF (HGF) is rare, affecting only one in $7,50,000$ people $(5,6)$.

\section{CLASSIFICATION}

The condition has been classified into 2 types; Nodular form characterized by presence of multiple tumors in the dental papillae and other form which is symmetric resulting in uniform enlargement of gingival and represents the most common type. There may be combination of both the types (8).

\section{HISTOLOGIC FEATURES}

Histopathologically, the bulbous increased connective tissue is relatively avascular and has densely arranged collagen-fibre bundles, numerous fibroblasts and mild chronic inflammatory cells $(6,24)$. The overlying epithelium is thickened and acanthotic, and has elongated rete ridges. The nodular appearance can be attributed to the thickened parahyperkeratinized epithelium (7). Unusual findings include the presence of small calcified particles, amyloid deposits, islands of odontogenic epithelium and osseous metaplasia in the connective tissue, and ulcerations of the overlying $\mathrm{mu}$ $\operatorname{cosa}(2,9)$.

\section{TREATMENT}

Although there is a large consensus on the modality of treatment to be performed in HGF patients, there are controversies among the authors with regard to the exact period in which it should be accomplished. According to several authors, the best time is when all of the permanent dentition has erupted, because the risk of recurrence is higher before it $(6,10,15,26)$. However, in some cases, a delay in the surgical treatment may cause significant consequences for the patients, such as primary dentition retention with delay in the eruption of the permanent teeth, difficulties in mastication and phonation, malpositioning of teeth, esthetic effects, and psychological problems for the patients and relatives $(4,10,17,18,20,27)$.

Treatment depends on the severity of enlargement and shows varying degree of success. When the enlargement is minimal, thorough scaling of teeth and home care may be all that are required to maintain good appearance. On the other hand, overgrowth tissues should be surgically removed (2).

Although recurrence is unpredictable, it is most often seen in children and teenagers rather than adults $(1,4)$. It has been demonstrated that recurrence is faster in areas with dental plaque accumulation $(18,27)$. 
However, Emerson demonstrated that the degree of enlargement did not appear to be related to the oral hygiene or to the amount of calculus present and that a correct physiologic contour of the marginal gingiva is more important to prevent recurrence (26). Normally, recurrence is minimal or delayed if good oral hygiene is achieved by a combination of monthly examinations with professional cleaning and oral hygiene instructions.

\section{DISCUSSION}

Gingival enlargement is a prevalent disease in children, conferring to the periodontist and the pediatric dentist an important role in the correct diagnosis and treatment of affected patients. Although association should be excluded, it is evident that most idiopathic gingival fibromatosis is seen in isolation. Isolated forms of idiopathic gingival fibromatosis are compatible with a normal life span, but the esthetic and dental associated alterations can considerably reduce quality of life and may result in serious emotional and social problems along with functional impairment.

\section{CONCLUSION}

In this case the deciduous teeth were partially embedded within gingival mass, causing severe functional and aesthetic problems to the child. A delayed gingivectomy could hamper the exfoliation of deciduous teeth and eruption of permanent teeth. Thus delaying gingivectomy to avoid recurrence in this case was considered inappropriate. A frequent follow up is required with surgical correction of any specific sites if needed. Psychological counseling is must for both patient and parents.

\section{REFERENCES}

1. Takagi $M$, Yamamoto $H$, Mega $H$, Hsieh KJ, Shioda S, Enomoto S. Heterogeneity in the gingival fibromatosis. Cancer 1991:68:2202-12.

2. Coletta RD, Graner E. Hereditary gingival fibromatosis: A systematic review. J Periodontol 2006;77:753-64.

3. Bozzo L, de Almeida OP, Scully C, Aldred MJ. Hereditary gingival fibromatosis: Report of an extensive four-generation pedigree. Oral Surg Oral Med Oral Pathol 1994;78:452-54.

4. Bozzo L, Machado MA, de Almeida OP, Lopes MA, Coletta RD. Hereditary gingival fibromatosis: Report of three cases. $J$ Clin Pediatr Dent 2000;25:41-46.

5. Anegundi RT, Sudha P, Nayak UA, Peter $J$. Idiopathic gingival fibromatosis-a case report. Hong Kong Dental Journal 2006;3:53-57.

6. Fletcher J. Gingival abnormalities of genetic origin: A preliminary communication with special reference to hereditary generalized gingival fibromatosis. J Dent Res 1966;45:597612.

7. Indu Shekhar KR. Idiopathic gingival fibromatosis. Saudi Dental Journal 2002; 14(3):143-45.

8. Tavargeri AK, Kulkarni SS, Sudha P, Basavprabhu. Idiopathic gingival fibromatosis-a case report. J Indian Soc Pedo Prev Dent 2004;22(4):180-82.

9. Chaturvedi R. Idiopathic gingival fibromatosis associated with generalized aggressive periodontitis: A case report. JADC 2009:75(4):291-95.

10. Bittencourt LP, Campos V, Moliterno LF, Ribeiro DP, Sampaio RK. Hereditary gingival fibromatosis: Review of the literature and a case report. Quintessence Int 2003;31:415-18.

11. Kelekis-Cholakis A,Wiltshire WA, Birek C. Treatment and long-term follow up of a patient with hereditary gingival fibromatosis: A case report. J Can Dent Assoc 2002;68:290-94.

12. Henefer EP, Kay LA. Congenital idiopathic gingival fibromatosis in the deciduous dentition: Report of a case. Oral Surg Oral Med Oral Pathol 1967;24:65-70.

13. Kratz CL, Morin CK. Hereditary gingival fibromatosis: A child affected with concurrent abnormalities. J Pedod 1987;11:187-92.

14. Danesh-Meyer MJ, Holborow DW. Familial gingival fibromatosis: a report of two patients. NZ Dent J 1993;89:11922.

15. Cuestas-Carnero R, Bornancini CA. Hereditary generalized gingival fibromatosis associated with hypertrichosis: Report of five cases in one family. J Oral Maxillofac Surg
1988;46:415-20.

16. Goldblatt J, Singer SL. Autosomal recessive gingival fibromatosis with distinctive facies. Clin Genet 1992;42:306-08.

17. Clocheret K, Dekeyser C, Carels C, Willems $\mathrm{G}$. Idiopathic gingival hyperplasia and orthodontic treatment: A case report. J Orthod 2003;30:13-19.

18. Kavvadia K, Pepelassi E, Alexandridis C, Arkadopoulou A, Polyzois G, Tossios K. Gingival fibromatosis and significant tooth eruption delay in an 11- year old male: $\mathrm{A}$ 30 month follow up. Int $J$ Paediatr Dent 2005;15:294-302.

19. Kamolmatyakul S, Kietthbthew S, Anusaksathien $O$. Long-term management of an idiopathic gingival fibromatosis patient with the primary dentition. Pediatr Dent 2001;23:508-13.

20. Baptista IP. Hereditary gingival fibromatosis: A case report. J Clin Periodontol 2002;29:871-74.

21. Doufexi A, Mina M, loannidou E. Gingival overgrowth in children: Epidemiology, pathogenesis and complications. A literature review. J Periodontol 2005;76 (1):3-10.

22. Casavecchia P, Uzel MI, Kantarci A, Hasturk H, Dibart S, Hart TC, Trackman $\mathrm{PC}$ et al. Hereditary gingival fibromatosis associated with generalized aggressive periodontitis: a case report. $J$ Periodontol 2004;75(5):770-78.

23. Holzhausen M, Ribeiro FS, Goncalves D, Correa FOB, Spolidorio LC, Orrico SRP. Treatment of gingival fibromatosis associated with Zimmermann-Laband syndrome. J Periodontol 2005;76(9): 1559-62.

24. Jaju PP, Desai A, Desai RS, Jaju SP. Idiopathic gingival fibromatosis- case report and its management. International Journal of Dentistry 2009, article ID 153603, 6 pages.

25. Narendra SK, Moharana DN, Satpathy N, Mahakur M. Idiopathic gingival enlargement in a family with autosomal dominant inheritance: A case report. Clinical video publications of medicosinternational.

26. Emerson TG. Hereditary gingival hyperplasia: A family pedigree of four generations. Oral Surg Oral Med Oral Pathol 1965;19:1-9.

27. Ramer M, Marrone J, Stahl B, Burakoff R. Hereditary gingival fibromatosis: Identification, treatment, control. J Am Dent Assoc 1996;127:493-95. 